\title{
Ion Trap Collision-Induced Dissociation of Multiply Deprotonated RNA: c/y-Ions versus (a-B)/w-Ions
}

\author{
Teng-yi Huang, Anastasia Kharlamova, Jian Liu, and Scott A. McLuckey \\ Department of Chemistry, Purdue University, West Lafayette, Indiana, USA
}

\begin{abstract}
The dissociation of model RNA anions has been studied as a function of anion charge state and excitation amplitude using ion trap collisional activation. Similar to DNA anions, the precursor ion charge state of an RNA anion plays an important role in directing the preferred dissociation channels. Generally, the complementary c/y-ions from 5' P-O bond cleavage dominate at low to intermediate charge states, while other backbone cleavages appear to a limited extent but increase in number and relative abundance at higher excitation energies. The competition between base loss, either as a neutral or as an anion, as well as the preference for the identity of the lost base are also observed to be charge-state dependent. To gain further insight into the partitioning of the dissociation products among the various possible channels, model dinucleotide anions have been subjected to a systematic study. In comparison to DNA, the 2'-OH group on RNA significantly facilitates the dissociation of the 5' $\mathrm{P}-\mathrm{O}$ bond. However, the degree of excitation required for a $5^{\prime}$ base loss and the subsequent $3^{\prime} \mathrm{C}-\mathrm{O}$ bond cleavage are similar for the analogous RNA and DNA dinucleotides. Data collected for protonated dinucleotides, however, suggest that the 2'-OH group in RNA can stabilize the glycosidic bond of a protonated base. Therefore, base loss from low charge state oligonucleotide anions, in which protonation of one or more bases via intramolecular proton transfer can occur, may also be stabilized in RNA anions relative to corresponding DNA anions. (J Am Soc Mass Spectrom 2008, 19, 1832-1840) (c 2008 American Society for Mass Spectrometry
\end{abstract}

$\mathrm{I}$ $t$ has been recognized that various noncoding RNA species play important roles in cellular function [1-4]. Recently, significant effort has been focused on the identification of these noncoding RNAs. However, conventional methods are usually labor intensive and ineffective in the characterization of RNA modifications [5]. On the other hand, tandem mass spectrometry is a rapid and sensitive alternative, provided the desired structural information can be derived from the dissociation chemistry that occurs between stages of mass analysis.

To develop tandem mass spectrometry-based RNA sequencing methods, an understanding of the factors that determine the nature of the structural information that can be obtained via dissociation of RNA ions is necessary. Some of the first studies on RNA dissociation were conducted with ions generated from fast atom bombardment (FAB). A variety of fragment ions, including the characteristic structural fragment $c_{x}$-ion, were identified [6,7]. The combination of matrixassisted laser desorption ionization (MALDI) and electrospray ionization (ESI) with tandem mass spectrometry facilitated the study of the gas-phase dissociation of

Address reprint requests to Dr. S. A. McLuckey, Department of Chemistry, Purdue University, 1393 Brown Laboratories, West Lafayette, IN 479071393, USA. E-mail: mcluckey@purdue.edu larger oligonucleotide ions. However, far more attention has been dedicated to the study of the dissociation behavior of DNA ions than to dissociation of RNA ions [8]. Using MALDI combined with a quadrupole/timeof-flight (Q/TOF) tandem mass spectrometer, Kirpekar and Krogh [9], for example, investigated the dissociation behavior of singly protonated RNA obtained by RNase digestion. Complex spectra with various types of fragment ions, including those resulting from neutral base losses, were observed. This work indicated that the $5^{\prime} \mathrm{P}-\mathrm{O}$ bond of the phosphodiester linkage was the most labile bond of the backbone. Schürch et al. [10] used a Q/TOF instrument to study the fragmentation of doubly and triply deprotonated mixed-sequence RNA/ DNA pentanucleotide ions derived from ESI. Positional selectivity of the neutral and charged base losses was observed. Unlike the RNA backbone cleavage observed in solution, a $5^{\prime} \mathrm{P}-\mathrm{O}$ backbone fragmentation mechanism involving the formation of an intramolecular cyclic transition-state with the 2 '- $\mathrm{OH}$ proton bridged to the $5^{\prime}$-phosphate oxygen followed by abstraction of the $2^{\prime}-\mathrm{OH}$ proton was proposed. In addition to the $\mathrm{c} / \mathrm{y}$-ion series, fragment ion series from other backbone bonds were also observed. Although all of the fragment ion types could provide sequence information, they also complicate the spectra and could lead to ambiguous peak assignments. The role of the $2^{\prime}-\mathrm{OH}$ group in the 
RNA 5' P-O bond cleavage was further established by using oligoribonucleotide analogs with an electronegative $2^{\prime}$-substituent, and the lack of a role for the nucleobase was indicated by using a deoxynucleotide without the nucleobase [11]. Recently, Kirpekar and coworkers used a hydrogen/deuterium exchange (H/DX) technique to study the different fragmentation behaviors of singly charged RNA and DNA cations using a MALDI TOF-TOF instrument. A mechanism similar to the RNA backbone cleavage in solution was proposed where a phosphorane intermediate is formed and leads to either the $5^{\prime} \mathrm{C}-\mathrm{O}$ bond cleavage or water loss. In addition, mechanisms for other dissociation channels were also proposed [12].

The major focus in the previous studies on RNA dissociation was to investigate the dominant dissociation channels upon beam-type collisional activation. Based on the current knowledge of the RNA characteristic dissociation channels, several noncoding RNAs bearing post-transcriptional modifications have been characterized using tandem mass spectrometry-based RNA sequencing methodologies. These RNA species are enzymatically digested into smaller fragments before being subjected to tandem mass spectrometry analysis [13-16]. However, a wide variety of dissociation channels are usually observed, which complicate spectral interpretation. The preferred dissociation channels for a given ion can be affected by numerous factors, such as the ion type (e.g., positive ion, negative ion, charge state, ionizing agent, etc.), the structure of the molecule, the internal energy distribution of the ion, and the time-frame over which the fragmentation reactions can evolve [8]. In this regard, the dissociation behavior of RNA ions is far from comprehensively characterized.

In this study, the dissociation of anions of a model RNA oligomer has been studied as a function of charge state and ion trap collisional activation conditions with a $\mathrm{Q} / \mathrm{TOF}$ tandem mass spectrometer capable of effecting ion trap collision-induced dissociation (CID) in the collision cell. Ion trap CID tends to favor the lowest energy dissociation pathways and to be more sensitive than beam-type CID to differences in the thresholds for such channels. This is because the ion trap CID process takes place over periods several orders of magnitude longer than beam-type CID and, as a result, samples lower rate processes that involve energies close to threshold [17]. Similar to DNA anions, the precursor ion charge state plays an important role in directing the preferred dissociation channels. Dramatic differences in the relative contributions of the competing dissociation channels are observed between different precursor ion charge states of the model oligomer. In addition, the amplitude of the applied excitation voltage has a significant effect on spectral complexity, in terms of types and abundances of the observed dissociation channels. The dissociation of RNA anions, however, is somewhat more complex than the dissociation of DNA anions in that cleavage of the $5^{\prime} \mathrm{P}-\mathrm{O}$ bond can be a dominant process in RNA under particular conditions whereas this process generally contributes little to the fragmentation of DNA anions. To reduce the number of confounding variables in comparing competing pathways in RNA anion dissociation, model dinucleotide systems have been studied. The energetics of each dissociation channel have been compared for the RNA dinucleotide and its DNA equivalent, with particular attention placed on the competing processes that lead to complementary c- and y-ions and complementary (a-B)and $\mathrm{w}$-ions. The results point to conditions that lead to extensive sequence information while minimizing spectral complexity.

\section{Experimental}

\section{Materials}

Methanol, isopropanol, and glacial acetic acid were purchased from Mallinckrodt (Phillipsburg, NJ). The RNA 8-mer (OH-GCGGAUUU-OH) was custom synthesized by Integrated DNA Technologies (Coralville, IA). RNA dinucleotides ( $\mathrm{rGpC}, \mathrm{rCpU}, \mathrm{rGpU}$, and $\mathrm{rUpU}), \mathrm{DNA}$ dinucleotides (dGpC, dCpT, dGpT, and $\mathrm{dTpT}$ ), ammonium acetate, and ethanol were obtained from Sigma-Aldrich (St. Louis, MO).

RNA and DNA dinucleotides were used without further purification. RNA 8-mer samples were desalted before mass spectrometric analysis. Desalting was carried out through repeated ethanol precipitation. Samples were first dissolved in ultrapure water. Precipitation was carried out by first adding $10 \mathrm{M}$ aqueous ammonium acetate to a RNA solution to bring the solution to $2.5 \mathrm{M}$ in ammonium acetate, followed by the addition of 2.5 volumes of ice-cold ethanol. After incubating at $-20^{\circ} \mathrm{C}$ for at least $2 \mathrm{~h}$, the RNA pellet was collected by centrifugation at room temperature for $40 \mathrm{~min}$ at 10,000 rpm. The supernatant was decanted, and the pellet was dried for $20 \mathrm{~min}$ in a centrifugal concentrator (SpeedVac UVS400; Savant, Holbrook, NY). The pellet was washed once with $200 \mu \mathrm{L}$ of cold ethanol and once with $70 \%$ aqueous ethanol by vortexing. This was followed by centrifugation of the sample for $20 \mathrm{~min}$ at 10,000 rpm, and then by drying the sample using SpeedVac. The above procedure was repeated at least twice. Following ethanol precipitation, the RNA pellet was stored at $-80^{\circ} \mathrm{C}$. It was resuspended in water to a concentration of 100 to $200 \mu \mathrm{M}$ as a stock solution just before mass spectrometric analysis. RNA solutions for negative nano-electrospray were prepared by diluting the aqueous stock solutions to ca. $20 \mu \mathrm{M}$ in $20 / 80$ ( $\mathrm{vol} / \mathrm{vol}$ ) isopropanol/water.

\section{Apparatus and Procedures}

All experiments were performed using a prototype version of a QqTOF tandem mass spectrometer (Q-Star Pulsar XL; SCIEX, Toronto, ON) modified to allow for ion/ion reaction studies [18]. Ionization was accomplished via a nano-ESI emitter for the formation of $(\mathrm{M}-\mathrm{nH})^{\mathrm{n}-}$ anions of RNA. To perform ion trap CID in 
Q2, Q1 selected precursor ions were injected into Q2 at relatively low kinetic energy and stored. A dipolar rf signal with frequency in resonance with the precursor ions was then applied to induce ion trap CID. A typical scan function consisted of RNA anion injection, isolation of ions of interest by Q1 in RF/DC mode, ion trap CID in Q2, and then mass analysis by TOF. To conduct pseudo-MS ${ }^{3}$ experiments, the RNA dinucleotide anions were fragmented in the atmosphere/vacuum interface by increasing the potential difference between the nozzle and skimmer. The fragment ions of interest were isolated in Q1 and then subjected to beam-type CID at a translational energy of $20 \sim 28 \mathrm{eV}$.

\section{Data Analysis}

The oligoribonucleotide molecular weight, electrospray series and the corresponding $\mathrm{m} / \mathrm{z}$ of RNA fragment ions were calculated using the Mongo Oligo Mass Calculator (http://library.med.utah.edu/masspec/mongo.htm) [19].

\section{Results and Discussion}

\section{Ion Trap Collision-Induced Dissociation of Multiply Deprotonated RNA $(M-n H)^{n-}$}

A mixed-base RNA oligomer, 5' OH-GCGGAUUU-3'OH, corresponding to the yeast tRNA ${ }^{\text {Phe }} 5^{\prime}$ terminal sequence was used in this study. To investigate the charge state effect on the dissociation of RNA anions, nano-ESI generated multiply deprotonated RNA anions [(M $2 \mathrm{H})^{2-}$ to $(\mathrm{M}-6 \mathrm{H})^{6-}$ ] were isolated and subjected to ion trap collision-induced dissociation under different excitation conditions. A variety of fragmentation reactions, including base loss, either as a neutral or as an anion, and various backbone cleavages, were observed among the charge states under different excitation amplitudes. Unlike DNA anions, which fragment predominantly through nucleobase loss followed by cleavage of the $3^{\prime}$ $\mathrm{C}-\mathrm{O}$ bond of the sugar from which the base was lost, the major dissociation channel of RNA is through $5^{\prime}$ $\mathrm{P}-\mathrm{O}$ bond cleavage, which has been shown to be independent of the nucleobase identity [11]. Figures 1 and 2 show two cases in which RNA anions of the lowest charge state $(\mathrm{M}-2 \mathrm{H})^{2-}$ and the highest charge state $(\mathrm{M}-6 \mathrm{H})^{6-}$ were dissociated under different excitation amplitudes. As shown in Figure 1, the (M $2 \mathrm{H})^{2-}$ RNA anion was dissociated efficiently upon ion trap collisional activation. Full sequence coverage was obtained from the RNA characteristic c/y-ion series when either low or high excitation amplitude was applied. (The formation of $\mathrm{c} / \mathrm{y}$-ions is generally not observed for DNA anions under ion trap collisional activation conditions.) The neutral base loss $(-\mathrm{BH})$, especially the loss of neutral guanine $(-\mathrm{GH})$, was also a dominant dissociation channel. The sporadic appearance of very low abundance product ions from other backbone cleavages was observed when low excitation amplitudes were applied. However, their abundances

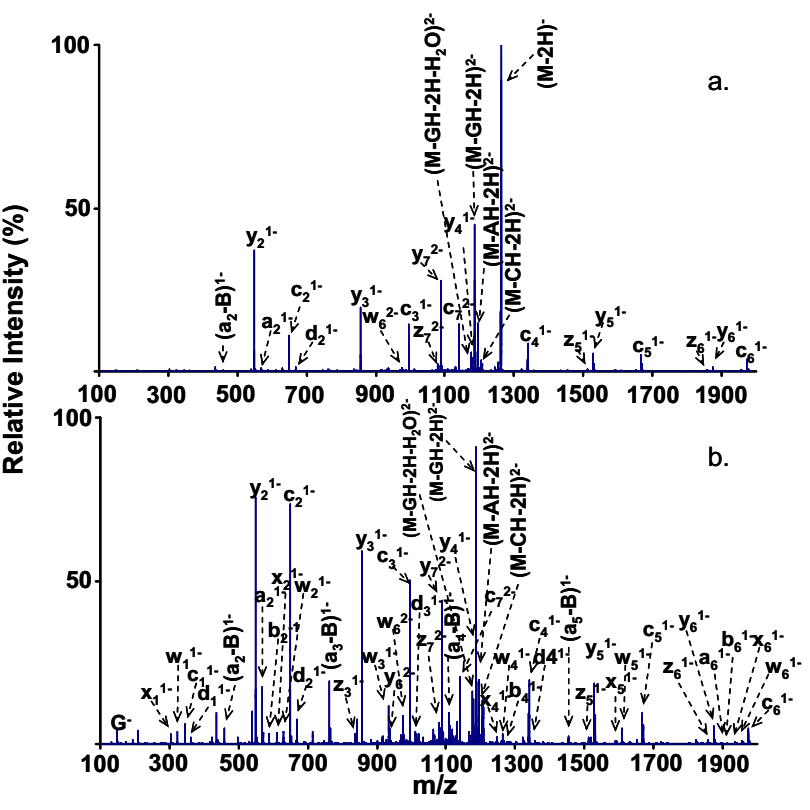

Figure 1. Ion trap tandem mass spectra of $(\mathrm{M}-2 \mathrm{H})^{2-}$ of $5^{\prime} \mathrm{OH}-G C G G A U U U-3^{\prime} \mathrm{OH}$ at (a) an excitation amplitude of 349 $\mathrm{mV}(34.48 \mathrm{kHz})$ and $(\mathbf{b})$ an excitation amplitude of $499 \mathrm{mV}(34.48$ $\mathrm{kHz})$.

were enhanced when higher excitation amplitudes were applied. These fragment ions, corresponding to the $\mathrm{a} / \mathrm{a}-\mathrm{B} / \mathrm{w}, \mathrm{b} / \mathrm{x}$ and $\mathrm{d} / \mathrm{z}$ ion series, also reflected RNA sequence but did not provide any information lacking from the $c / y$ ions. Among the alternate sequence ion series, the $\mathrm{a} / \mathrm{a}-\mathrm{B} / \mathrm{w}$-ion series was the most abundant and provided extensive sequence coverage at the higher excitation amplitude.

A dramatic change in the dissociation behavior was observed for the $(\mathrm{M}-6 \mathrm{H})^{6-}$ anion (Figure 2) relative to the $(\mathrm{M}-2 \mathrm{H})^{2-}$ precursor ion. Loss of charged adenine $\left(\mathrm{A}^{-}\right)$was the dominant dissociation channel and no backbone cleavage was observed when low excitation amplitude was applied (Figure 2a). An incremental increase in excitation amplitude led to the simultaneous increase of the complementary ions derived from charged base loss ions, $\left(\mathrm{M}-6 \mathrm{H}-\mathrm{A}^{-}\right)^{5-}$ and $\mathrm{A}^{-}$. As the excitation amplitude was increased further, the intensity of the $(\mathrm{M}-$ $\left.6 \mathrm{H}-\mathrm{A}^{-}\right)^{5-}$ ion decreased relative to that of $\mathrm{A}^{-}$. Other charged base loss ions and fragment ions from backbone cleavage were generated with higher intensities. A relatively high percentage of the fragment ions observed at higher amplitude (Figure $2 b$ ) resulted from the cleavage of $3^{\prime} \mathrm{C}-\mathrm{O}$ bonds, with the cleavage to give the $\mathrm{a}_{5}-\mathrm{A} / \mathrm{w}_{3}$ products being particularly prominent (i.e., products from further dissociation of the $\left(\mathrm{M}-6 \mathrm{H}-\mathrm{A}^{-}\right)^{5-}$ ion). Fragment ions corresponding to other dissociation channels were also observed, however, at much lower abundance. The most striking contrast between the high and low charge state precursor ions was that the $\mathrm{c} / \mathrm{y}$-ion series was dominant at the lower charge state but was not at the higher charge state under any activation condition. A proposed mechanism for the $5^{\prime} \mathrm{P}-\mathrm{O}$ bond cleavage of 


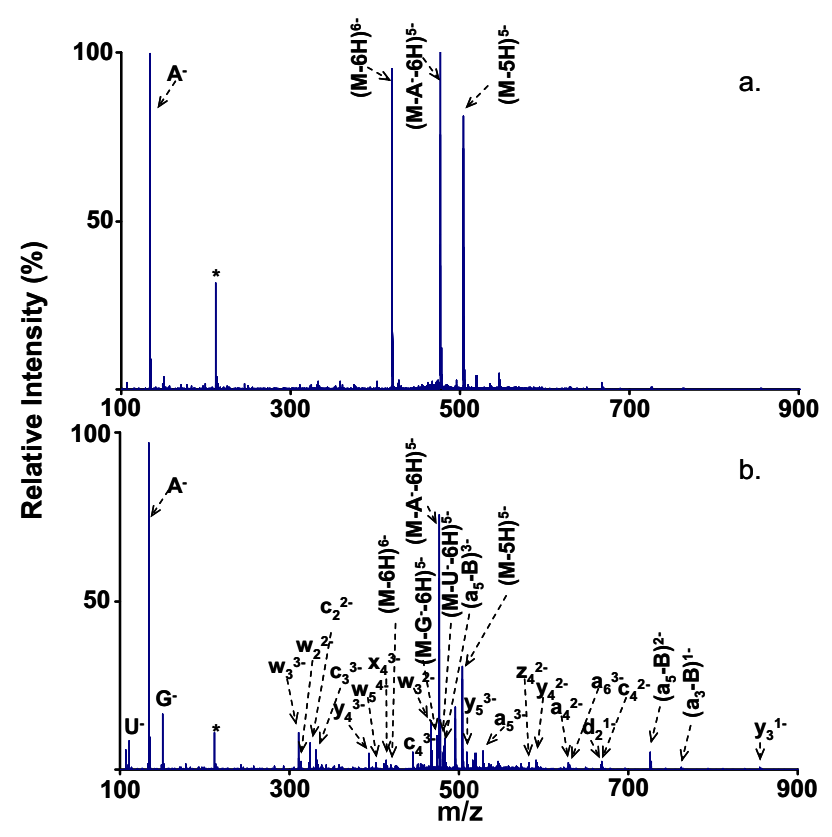

Figure 2. Ion trap tandem mass spectra of the $(\mathrm{M}-6 \mathrm{H})^{6-}$ ion of 5' OH-GCGGAUUU-3' $\mathrm{OH}$ at (a) an excitation amplitude of $80 \mathrm{mV}$ $(103 \mathrm{kHz})$ and $(\mathbf{b})$ an excitation amplitude of $100 \mathrm{mV}(103 \mathrm{kHz})$. (The $(\mathrm{M}-5 \mathrm{H})^{5-}$ was formed from ion/molecule reaction with the $n$-butylbenzenesulfonamide that entered from the tubing of the gas supply and was present with the isolated $(\mathrm{M}-6 \mathrm{H})^{6-}$ ion. It was not subjected to collisional activation. The asterisk denotes the deprotonated $n$-butylbenzenesulfonamide anion.

RNA posits the initiation of the reaction by the formation of an intramolecular cyclic intermediate through the bridging between the $2^{\prime}-\mathrm{OH}$ hydrogen and the $5^{\prime}$ phosphate oxygen. Abstraction of the $2^{\prime}-\mathrm{OH}$ proton by the $5^{\prime}$ oxygen then leads to the dissociation of the $5^{\prime} \mathrm{P}-\mathrm{O}$ bond. It is apparent that base loss, particularly charged base loss, becomes more competitive as the oligonucleotide charge increases relative to the backbone cleavage mechanism that leads to $c / y$-ions. It is well-known that the loss of $\mathrm{A}^{-}$is a dominant process for highly charged
DNA oligonucleotide anions that contain an adenosine residue. The charged base loss channel likely plays a role in the increased competitiveness of the a-B/w fragmentation channel relative to the $\mathrm{c} / \mathrm{y}$ cleavage channel.

Figures 3 and 4 summarize the charge state dependent and excitation amplitude dependent dissociation results for the $\mathrm{c} / \mathrm{y}$-ion series (Figure 3 ) and for the $\mathrm{a} / \mathrm{a}-\mathrm{B} / \mathrm{w}$-ion series (Figure 4) for all of the examined charge states of the RNA oligomer. The relative abundance of a dissociation channel was calculated by dividing the sum of the ion abundances corresponding to a particular channel (e.g., the sum of the complementary c- and y-ion abundances) by the total abundance of all product ions identified in a product ion spectrum. Internal fragment ions from sequential backbone dissociation reactions were usually present at very low abundance and were not included in the total fragment ion abundance tally. Dramatic changes in the preference of each dissociation channel were observed among different precursor ion charge states, as shown in the plots of relative intensity versus dissociation channel for each type of dissociation channel.

For the $\mathrm{c} / \mathrm{y}$-ion series (Figure 3), the relative contribution of each channel varied significantly among charge states. However, full sequence coverage was usually obtained at lower charge states, while lower sequence coverage from $\mathrm{c} / \mathrm{y}$ cleavages was noted at higher charge states. The excitation amplitude did not significantly affect the preference of dissociation channels or the sequence coverage, except for the (M $6 \mathrm{H})^{6-}$ precursor ion. At the $6-$ charge state, higher excitation amplitudes were required to observe contributions from the dissociation of $5^{\prime} \mathrm{P}-\mathrm{O}$ bonds. As for the non-c/y ions, minor evidence, at most, for the products from the relevant dissociation channels was observed among different charge states at low amplitude. As a result, the sequence coverage was low compared to the usually full sequence coverage from the $\mathrm{c} / \mathrm{y}$-ion series. The sequence coverage from the
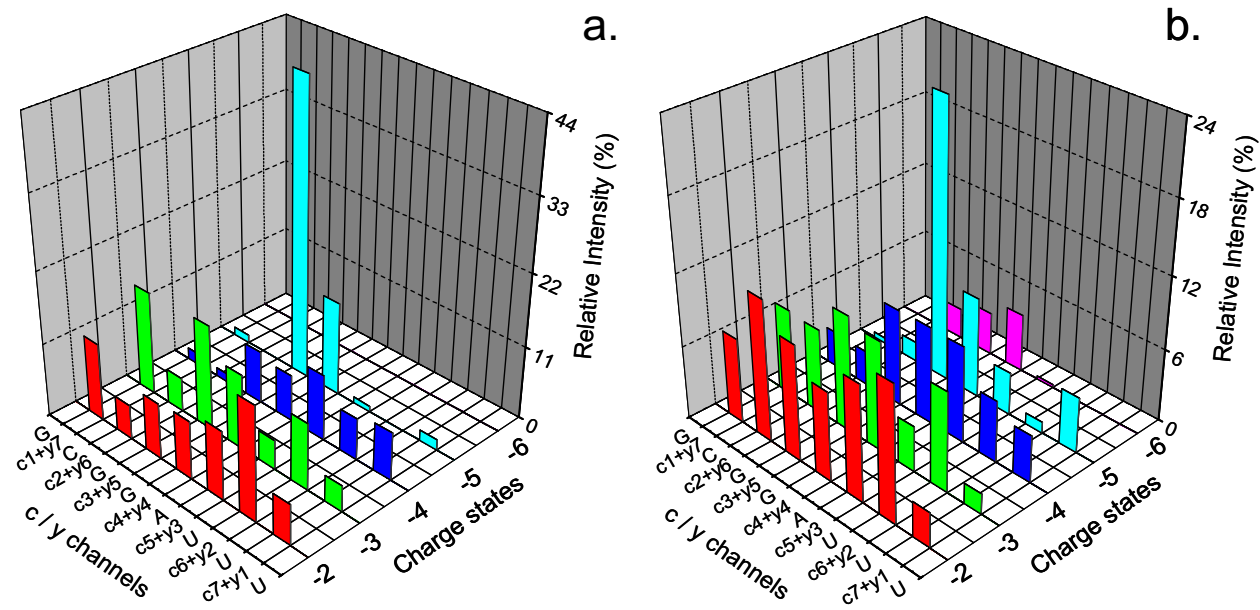

Figure 3. Relative abundance of the $\mathrm{c} / \mathrm{y}$-ion series at various charge states ( -2 to -6$)$ (a) at lower excitation amplitudes and (b) at higher excitation amplitudes. 

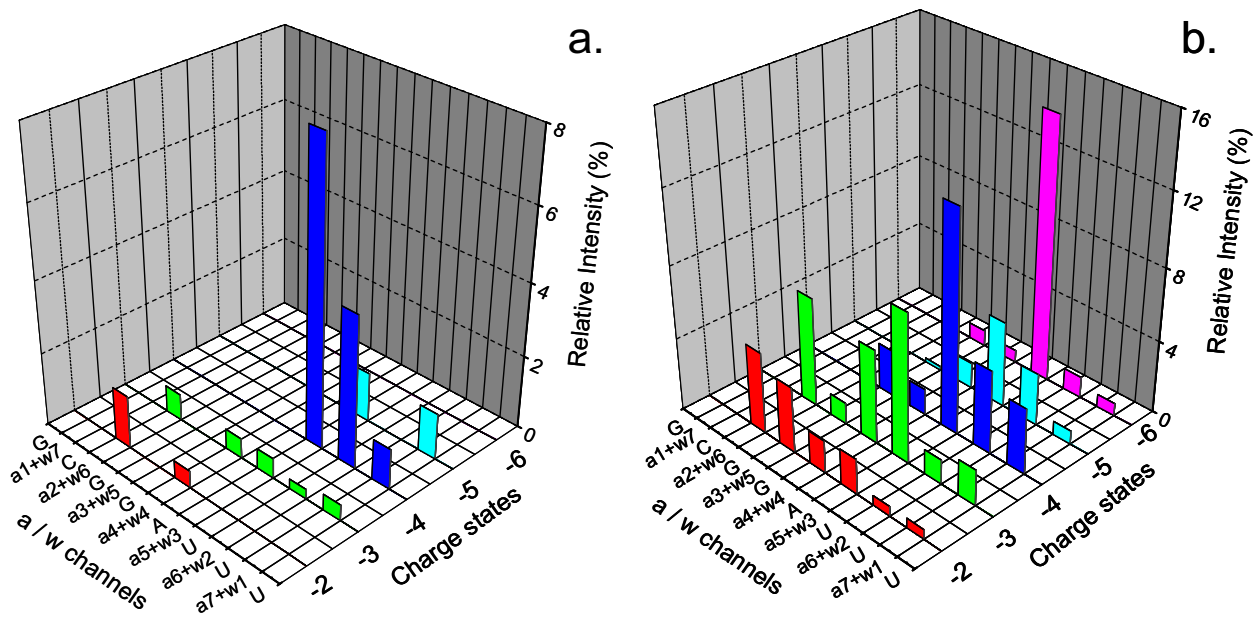

Figure 4. Relative abundance of the a/a-B/w-ion series at various charge states $(-2$ to -6$)$ (a) at lower excitation amplitudes and (b) at higher excitation amplitudes.

non-c/y-ion series, however, could be improved by applying higher amplitude excitation voltages. As an example, Figure 4 summarizes the charge state and excitation amplitude dependences for the $\mathrm{a} / \mathrm{a}-\mathrm{b} / \mathrm{w}$-ion series. (The behaviors of the $b / x-$ and $d / z$-ion series, which were observed at relatively low abundances, are provided as Supplementary material, which can be found in the electronic version of this article.)

The effect of precursor ion charge state and excitation amplitude on base loss was also investigated (see Supplementary data). Similar to DNA, the preference for either neutral or charged base loss is determined by precursor ion charge state or "charge level" [20,21]. At lower charge states, neutral base loss dominated. At intermediate charge states, both neutral and charged base losses were observed. At higher charge states, charged base loss dominated. The competition of the neutral and charged base loss for DNA has been rationalized on the basis of a proton-bound dimer intermediate model [20, 22, 23]. Increasing the charge states increases the electrostatic repulsion in the ion and therefore favors charge separation reactions. The loss of individual nucleobases also follows different trends among different charge states. The preference of charged base loss followed $\mathrm{A}^{-}>\mathrm{G}^{-}>\mathrm{U}^{-}>\mathrm{C}^{-}$at charge levels higher than $50 \%$ (4- to 6 - charge states), and $\mathrm{G}^{-}>\mathrm{A}^{-}>\mathrm{U}^{-}>\mathrm{C}^{-}$at charge levels lower than $50 \%$ (2- and $3-$ charge states). There was also variation observed for the preference of neutral base losses with precursor ion charge state. The preference of neutral base loss followed $-\mathrm{AH}>-\mathrm{GH}>-\mathrm{CH}>-\mathrm{UH}$ at charge levels higher than $50 \%$ (4- to 6 - charge states), and $-\mathrm{GH}>-\mathrm{AH}>-\mathrm{CH}>-\mathrm{UH}$ at charge levels lower than 50\% (2- and 3- charge state) (Figure 5a). These trends are similar to those noted for DNA anions in that $-\mathrm{AH}$ is preferred over $-\mathrm{CH}$ and $-\mathrm{GH}$ at higher charge states, and the terminal bases are preferred over the internal bases at lower charge states [21].

Figure 5 summarizes the contributions of the various dissociation channel types as a function of charge state at relatively low and relatively high excitation amplitudes. Clearly 5' P-O bond cleavage and base loss are competing processes and that both are relatively low-energy processes. As a result, they are particularly dominant at low excitation energies and, in the case of the model system studied here, give rise to most of the fragment ion signals $(>85 \%)$ at low activation amplitudes for all charge states. The other backbone cleavages, including the $3^{\prime} \mathrm{C}-\mathrm{O}$ bond cleavage that follows base loss, can be increased significantly at high activation energy. In the case of a-B/w ion formation, higher excitation amplitudes are presumably required to drive the second step of the two step process that leads to these complementary pairs. It is noteworthy that sequence coverage, in general, tends to be highest at the lower charge states. Charged base loss tends to become increasingly facile with increasing precursor ion charge state and the loss of charged adenine tends to become particularly favored. As a result, much of the fragmentation is directed to the sites of the adenosine residues, thereby minimizing the breadth of sequence coverage. A similar trend has been noted with small DNA oligomer anions as well [21, 24, 25]. For the purpose of using tandem mass spectrometry for RNA sequencing, it is desirable to maximize sequence information while minimizing sequential fragmentation that does not provide useful information (e.g., processes that lead to internal fragments). The use of moderate to low excitation amplitudes minimizes sequential fragmentation and the selection of relatively low charge states minimizes the likelihood for a dominant charged base loss channel that outcompetes other structurally informative dissociation channels.

\section{Comparison of DNA and RNA Dinucleotide Dissociation}

To clarify the possible origins of the major product ions noted for the RNA oligomer dissociation, several RNA 


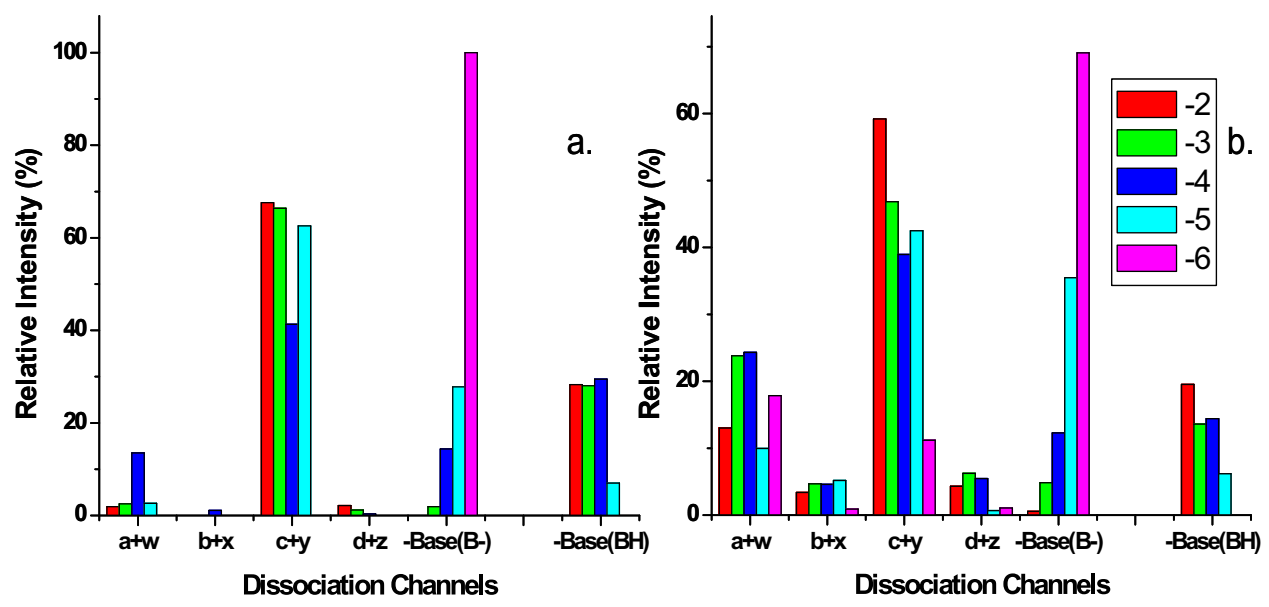

Figure 5. Relative contribution of each major dissociation channel at various charge states ( -2 to -6$)$ (a) at low excitation amplitudes and (b) at higher excitation amplitudes. The $\mathrm{c} / \mathrm{y}$-ion series and base loss species are generally the dominant products. The abundances of the other non-c/y-ion series increase at higher excitation energy.

dinucleotides were subjected to pseudo-MS ${ }^{3}$ experiments, where the first dissociation step was effected in the ion source atmosphere/vacuum region. All RNA dinucleotide anions dissociated to give a common set of ion types including $(\mathrm{M}-\mathrm{H}-\mathrm{CONH})^{-}[6],\left(\mathrm{M}-\mathrm{H}-3^{\prime} \mathrm{BH}\right)^{-},(\mathrm{M}$ $\left.-\mathrm{H}-5^{\prime} \mathrm{BH}\right)^{-}, 5^{\prime} \mathrm{B}^{-}, \mathrm{d}-, \mathrm{c}^{-}, \mathrm{w}^{-}$, and $\mathrm{x}$-ions, as well as ions observed at $\mathrm{m} / \mathrm{z} 211$ and 193 . The $\mathrm{m} / \mathrm{z} 211$ and 193 ions correspond to $\left(\mathrm{PO}_{7} \mathrm{C}_{5} \mathrm{H}_{8}\right)^{-}$and $\left(\mathrm{PO}_{6} \mathrm{C}_{5} \mathrm{H}_{6}\right)^{-}$, respectively. The RNA dinucleotide anions were fragmented in the source interface region, and the neutral loss ions were isolated in Q1 and then subjected to beam-type $\mathrm{CID}$ at a kinetic energy of $28 \mathrm{eV}$. The pseudo-MS ${ }^{3}$ spectra of several first generation products ions from $\mathrm{rGpC}$ are provided as supplementary material. These include the $(\mathrm{M}-\mathrm{H}-\mathrm{CONH})^{-},\left(\mathrm{M}-\mathrm{H}-3^{\prime} \mathrm{BH}\right)^{-}$, and $\left(\mathrm{M}-\mathrm{H}-5^{\prime} \mathrm{BH}\right)^{-}$ions. Dissociation of the $(\mathrm{M}-\mathrm{H}-$ $\mathrm{CONH})^{-}$ion mostly led to the generation of the d-ion. Lower intensity c- and $\mathrm{w}$-ions were also observed. Dissociation of $\left(\mathrm{M}-\mathrm{H}-3^{\prime} \mathrm{BH}\right)^{-}$led to a similar abundances of c- and d-ions. Dissociation of $(\mathrm{M}-\mathrm{H}-$ $\left.5^{\prime} \mathrm{BH}\right)^{-}$, which is, by far, the most abundant first generation neutral loss product, predominantly led to the generation of the $\mathrm{w}$-ion and a low intensity of $\mathrm{x}$-ion. The two-step process of $5^{\prime}$ base loss followed by the $3^{\prime} \mathrm{C}-\mathrm{O}$ cleavage in the RNA anion is similar to that of DNA, suggesting a common mechanism. Similar behavior was observed in the pseudo-MS ${ }^{3}$ of the $(\mathrm{M}-6 \mathrm{H}-$ $\left.\mathrm{A}^{-}\right)^{5-}$ and $\left(\mathrm{M}-5 \mathrm{H}-\mathrm{A}^{-}\right)^{4-}$ ions from the model RNA 8-mer (see Supplementary data), where the dissociation of the $\mathrm{A}^{-}$loss species gave rise to complementary $\mathrm{a}_{5}-\mathrm{B} / \mathrm{w}_{3}$ ion pairs as the dominant dissociation channel.

The MS/MS and $\mathrm{MS}^{3}$ strongly suggest that the c-ions are primarily formed as first generation products. While the dissociation of $\left(\mathrm{M}-\mathrm{H}-3^{\prime} \mathrm{BH}\right)^{-}$and $(\mathrm{M}-\mathrm{H}-$ $\mathrm{CONH})^{-}$also gave rise to c-ions, other second generation products were much more abundant. Since the generation of both $(\mathrm{M}-\mathrm{H}-\mathrm{CONH})^{-}$and $\left(\mathrm{M}-\mathrm{H}-3^{\prime} \mathrm{BH}\right)^{-}$ requires higher excitation amplitudes and are both present at a relatively low abundance themselves, the sequential fragmentation of these ions would need even more internal energy deposition from activation. The (M $\left.-\mathrm{H}-5^{\prime} \mathrm{BH}\right)^{-}$ion, which is the most abundant first generation product, cannot give rise to a c-ion because the $5^{\prime}$ base is missing. The fragment ions, $\mathrm{c}^{-}, \mathrm{x}-, \mathrm{W}-$-, and d-ions were all subjected to beam-type CID (data not shown). From these studies, it was clear that the $m / z 211$ ion is formed primarily from the loss of $\mathrm{B}_{2} \mathrm{H}$ from the $\mathrm{w}$-ion (i.e., it is the (w-3' BH) $)^{-}$species) while the $m / z 193$ ion is formed primarily via cleavage of the $5^{\prime} \mathrm{P}-\mathrm{O}$ bond from the $\left(\mathrm{M}-\mathrm{H}-5^{\prime} \mathrm{BH}\right)^{-}$ion (i.e., it is the (c-5' $\left.\mathrm{BH}\right)^{-}$species).

The key difference between the dissociation behaviors of RNA anions and DNA anions is the facile $5^{\prime} \mathrm{C}-\mathrm{O}$ bond cleavage channel that is present in RNA but not in DNA. This difference presumably arises from the presence of the $2^{\prime}-\mathrm{OH}$ group in RNA, which is the only significant structural difference between the inter-residue regions of the two oligomer types. It is of interest to determine if the presence of the $2^{\prime}-\mathrm{OH}$ group in RNA either enables the 5' $\mathrm{P}-\mathrm{O}$ bond cleavage, inhibits base loss and/or the subsequent formation of $\mathrm{a}-\mathrm{B} / \mathrm{w}$ ions, or both. To address these questions, the fragmentations of DNA and RNA anions of the same or similar dinucleotides and their dependence on the excitation amplitude have been examined. The energetic aspects of DNA dinucleotide dissociation have been studied [22, 23] but no corresponding studies on RNA have been reported. Four sets of RNA and DNA dinucleotide monophosphates (rGpC, rCpU, rGpU, and $\mathrm{rUpU}$; $\mathrm{dGpC}, \mathrm{dCpT}, \mathrm{dGpT}$, and $\mathrm{dTpT}$ ) were used in this comparative study. The nano-ESI generated singly deprotonated precursor ions were isolated and subjected to ion-trap CID at various excitation amplitudes. The relative abundance of each ion was plotted as a function of the excitation amplitude applied in the ion trap collisional activation of each dinucleotide precursor ion. The data for the $\mathrm{rGpC}$ and $\mathrm{dGpC}$ anions illustrate the general observations noted 
for all of the DNA/RNA dinucleotide comparisons (Figure 6). As shown in Figure 6a, the c-ion from the 5' $\mathrm{P}-\mathrm{O}$ bond cleavage, and $5^{\prime}$ base loss, either as an anion $\left(5^{\prime} \mathrm{B}^{-}\right)$or as a neutral $\left(\mathrm{M}-\mathrm{H}-5^{\prime} \mathrm{BH}\right)^{-}$, are the dominant fragmentation channels for RNA. In the case of the $\mathrm{rGpC} / \mathrm{dGpC}$ and $\mathrm{rGpU} / \mathrm{dGpT}$ comparisons (see Supplementary data), the formation of the c-ion clearly shows a lower excitation threshold compared to the base loss. In the cases of the $\mathrm{rCpU} / \mathrm{dCpU}$ and $\mathrm{rUpU} /$ dTpT comparisons (see Supplementary data), the formation of c-ions and ( $\left.\mathrm{M}-\mathrm{H}-5^{\prime} \mathrm{BH}\right)$ ions appeared to occur at very similar excitation amplitudes. In all cases, these two channels were observed to show the lowest excitation amplitude thresholds. In all cases, increasing the excitation amplitude led to the appearance of higher energy dissociation channels and/or products from sequential dissociation, such as $(\mathrm{M}-\mathrm{H}-\mathrm{CONH})^{-}$, $(\mathrm{M}$ $\left.-\mathrm{H}-3^{\prime} \mathrm{BH}\right)^{-}$, the $\mathrm{w}^{-}, \mathrm{d}-, \mathrm{x}$-ions, and the $\left(\mathrm{w}^{-} 3^{\prime} \mathrm{BH}\right)^{-}$ and $\left(\mathrm{c}-5^{\prime} \mathrm{BH}\right)^{-}$ions discussed above. Clearly lower excitation energies are required for the $5^{\prime} \mathrm{P}-\mathrm{O}$ bond cleavage ( $\mathrm{c} / \mathrm{y}$ ion channel) compared to the $3^{\prime} \mathrm{C}-\mathrm{O}$ bond cleavage channel that follows base loss $(a-B / w)$. Also, the intensities of the $d$ and $x$ ions were significantly lower than the $\mathrm{c}$ and $\mathrm{w}$ ions, and were observed only at relatively high amplitudes, where secondary fragmentations usually occur. The $(\mathrm{M}-\mathrm{H}-\mathrm{CONH})^{-}$ and $\left(\mathrm{M}-\mathrm{H}-3^{\prime} \mathrm{BH}\right)^{-}$ions also required relatively high excitation amplitudes and, when present, were observed at relatively low abundances. (No $(\mathrm{M}-\mathrm{H}-$ $\mathrm{CONH})^{-}$ions, however, were observed from the RNA 8-mer anions for any of the precursor ion charge states.)
The dissociation of the DNA dinucleotide is significantly different, as illustrated in Figure $6 \mathrm{~b}$ for the $\mathrm{dGpC}$ anion. The fragment ions from ion trap CID of the DNA dinucleotide anion included $(\mathrm{M}-\mathrm{H}-\mathrm{CONH})^{-},(\mathrm{M}-\mathrm{H}$ $\left.-3^{\prime} \mathrm{BH}\right)^{-},\left(\mathrm{M}-\mathrm{H}-5^{\prime} \mathrm{BH}\right)^{-}, 5^{\prime} \mathrm{B}^{-}$, the d-ion, the w-ion, and an ion at $\mathrm{m} / \mathrm{z} 195$, which is the analog of the $\mathrm{m} / \mathrm{z} 211$ ion from the $\mathrm{rGpC}$ anion (i.e., it is primarily formed from $3^{\prime}$ base loss from the w-ion). The major contrast between the RNA and DNA dinucleotide dissociation behavior is that no c-ions were observed for any of the DNA dinucleotides studied. The $5^{\prime}$ nucleobase loss is the lowest energy channel. Also, by increasing the excitation amplitude, fragment ions from backbone cleavages $\mathrm{w}$ - and, to a lesser degree, d-ions were observed.

The comparison of the two plots in Figure 6, as well as the comparisons of the other model dinucleotides (see Supplementary data), indicate that the presence of the 2 '-OH group has little effect on the facility with which base loss occurs from the dinucleotide anions. Rather, it facilitates the $5^{\prime} \mathrm{P}-\mathrm{O}$ cleavage that leads to complementary c- and y-ions. It is also of interest to determine if the presence of the 2'-OH group has an effect on the second step of the two-step mechanism, which consists of a $5^{\prime}$ base loss followed by cleavage of the $3^{\prime} \mathrm{C}-\mathrm{O}$ bond of the sugar from which the base was lost. To address this question, the excitation amplitude dependences of the fragmentation of the $\left(\mathrm{M}-\mathrm{H}-5^{\prime} \mathrm{BH}\right)^{-}$anions of $\mathrm{rGpC}$ and $\mathrm{dGpC}$ were examined (see Supplementary data). This comparison revealed that both $\left(\mathrm{M}-\mathrm{H}-5^{\prime} \mathrm{BH}\right)^{-}$anions show facile formation of a $\mathrm{w}$-type ion as the dominant cleavage with little difference in excitation amplitude

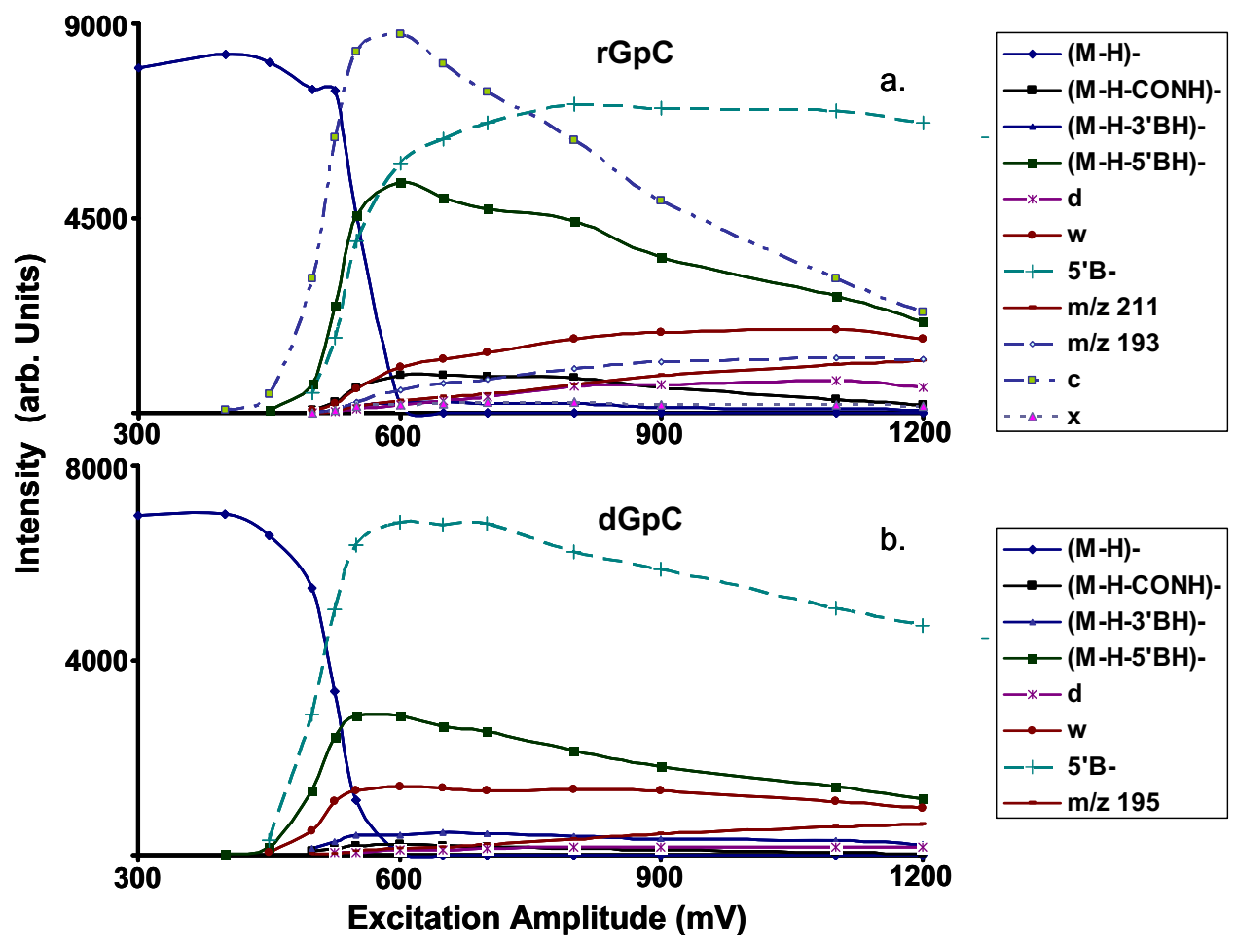

Figure 6. Excitation amplitude dependence of the product ion spectra for deprotonated (a) RNA $\mathrm{rGpC}$, and (b) DNA dGpC. Various types of ions are indicated in the figure legends on the right. 
dependence. Hence, the presence of the $2^{\prime}-\mathrm{OH}$ group in the RNA anion apparently has very little effect on the mechanism of the $\mathrm{w}$-ion formation.

Based on the tendency of fragmentation in negative MALDI TOF experiments, it has been concluded that RNA is more stable than DNA in the gas phase [26, 27]. The electronegative 2'-OH group on RNA has been considered to stabilize the $\mathrm{N}$-glycosidic bond, which makes the loss of the nucleobase and the subsequent cleavage of the 3' C-O bond more difficult in RNA than in DNA. On the basis of the comparison of the RNA and DNA dinucleotide anions, stabilization of the nucleobase by a 2'-OH group is not apparent. However, a reviewer has pointed out that singly charged oligonucleotide anions with multiple phosphodiester linkages allow for proton transfer from the backbone to the nucleobase. Strong evidence for this scenario has been presented in the case of DNA anions of relatively low charge [28-30]. Hence, the presence of the 2'-OH group in RNA oligonucleotide anions of relatively low charge, for which intramolecular proton transfer can occur, may lead to stabilization of glycosidic bonds and thereby stabilize the oligomer with respect to base loss. To examine the possibility for the gas-phase stabilization of a protonated nucleobase by a $2^{\prime}-\mathrm{OH}$ group, we compared the excitation energy dependences of the singly protonated dinucleotides $\mathrm{rGpC}$ and $\mathrm{dGpC}$. In this case, the 2'-OH group appears to stabilize the dinucleotide with respect to base loss when the base is protonated (see Figure 7). Hence, in the case of oligomers of relatively low charge and with available proton counterions to transfer from the phosphodiester linkage, intramo- lecular proton transfer to the nucleobase could lead to stabilization of RNA anions of relatively low charge. Hence, the role of the 2'-OH group in RNA can be 2-fold in the case of the ions of low charge in that it opens up a new low-energy channel and likely stabilizes RNA fragmentation with respect to base loss. As the anion charge state increases, the mechanism for glycosidic bond stabilization becomes less likely due both to fewer available protons to transfer to nucleobases and to the higher energy costs associated the intramolecular charge separation that occurs upon proton transfer.

\section{Conclusions}

The dissociation of nano-ESI-generated RNA anions has been studied using ion trap collisional activation on a hybrid quadrupole time-of-flight (QqTOF) tandem mass spectrometer. Clearly the information content from tandem mass spectrometry can be affected by the precursor ion charge state and excitation energy. Generally, the $\mathrm{c} / \mathrm{y}$-ion series and base losses are the lowest energy dissociation channels. The cleavage of the $5^{\prime} \mathrm{P}-\mathrm{O}$ bond dominated at low to medium charge states when low excitation amplitudes were applied, while contributions from cleavages of the other backbone bonds increased at higher excitation amplitudes. Similar to DNA, the a-B/wion series resulted from the sequential cleavage involving $5^{\prime}$ base loss followed by the $3^{\prime} \mathrm{C}-\mathrm{O}$ bond cleavage from the sugar involved in the base loss. The dissociation of model dinucleotide systems showed that the two-step cleavage process leading to $\mathrm{a}-\mathrm{B} / \mathrm{w}$ ions is very similar for

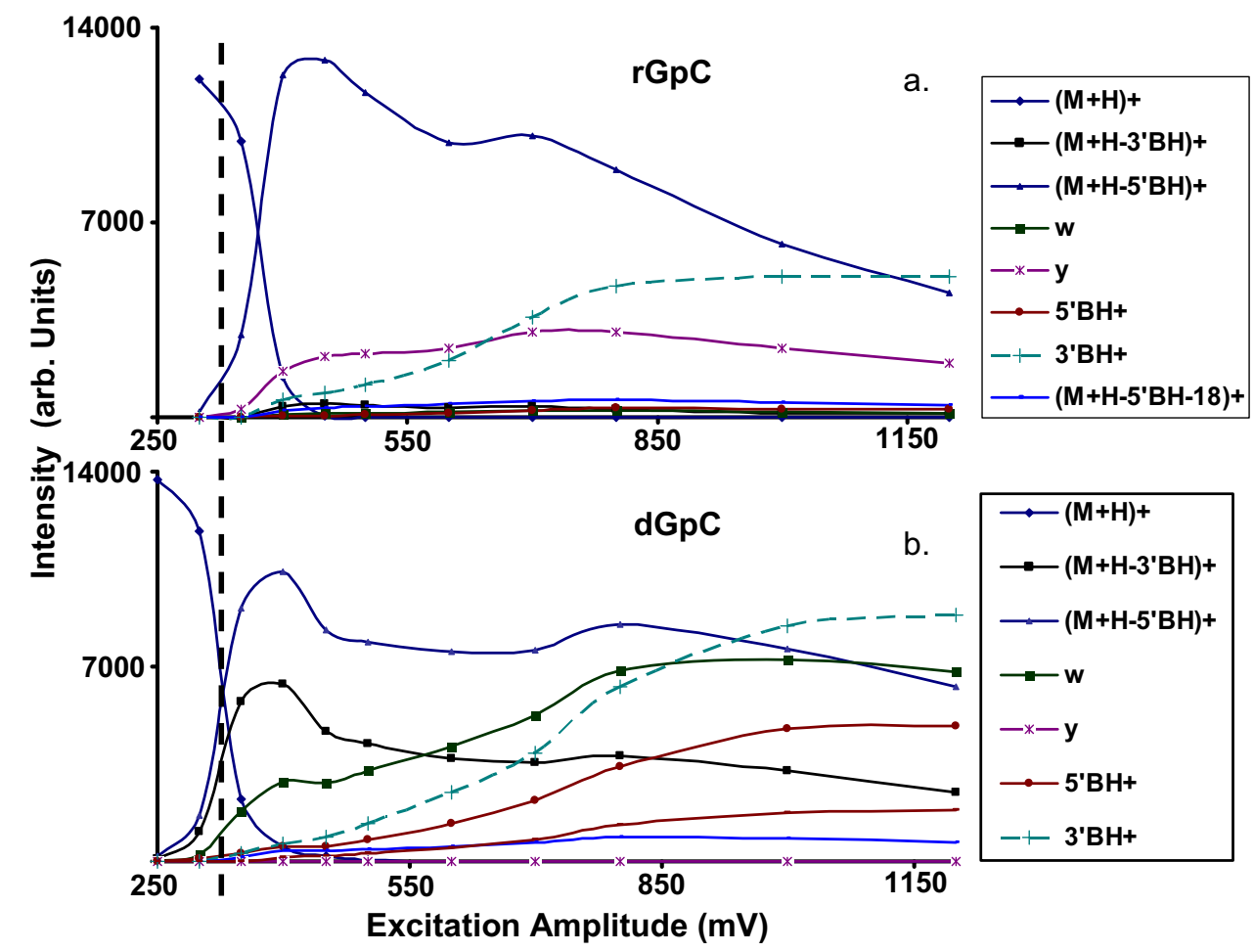

Figure 7. Excitation amplitude dependence of the product ion spectra for protonated (a) RNA rGpC, and (b) DNA dGpC. Various types of ions are indicated in the figure legends on the right. 
RNA and DNA systems and that the presence of the $2^{\prime}-\mathrm{OH}$ group in RNA has little influence on the energetic requirements for either base loss or the subsequent backbone cleavage when intramolecular proton transfer to a nucleobase does not or cannot occur (as is the case with deprotonated dinucleotides). However, in the case of the comparison of protonated RNA and DNA dinucleotides, the 2'-OH group of the RNA tends to stabilize the base loss channel. Hence, when intramolecular proton transfer can occur in RNA oligonucleotide anions, which is most likely at relatively low charge states, the base loss channel may be affected by the 2'-OH group. The $5^{\prime} \mathrm{P}-\mathrm{O}$ bond cleavage that leads to complementary c- and y-ions, however, is significantly facilitated by the $2^{\prime}-\mathrm{OH}$ group on RNA regardless of the protonation state of the nucleobase. This process was found to be either more facile or comparably facile to base loss. Higher excitation amplitudes were required for observation of $\mathrm{a}-\mathrm{B} / \mathrm{w}$-ions than for $c / y$-ion because the former ions require higher excitation amplitudes to drive the two-step process. Other backbone cleavages, such as those leading to complementary $b / x-$ and $\mathrm{d} / \mathrm{z}$-ions, occur at relatively high excitation amplitudes, and can be observed at relatively low abundances along with the more abundant $\mathrm{c} / \mathrm{y}$ and $\mathrm{a}-\mathrm{B} / \mathrm{w}$ ions.

These results provide insights into ion trap collisional activation conditions that maximize structural information while minimizing spectral complexity. First, it is likely to be generally desirable to avoid high charge states that tend to favor charged base loss. A high degree of selectivity is noted at high charge states for loss of deprotonated adenine, as has also been noted for DNA anions. This tends to restrict backbone cleavages to adenosine residues, which minimizes sequence coverage. The activation of relatively low charge state precursor ions at relatively low excitation amplitudes favors cleavages at the $5^{\prime} \mathrm{P}-\mathrm{O}$ bond. This process tends to be less selective than the two-step cleavage that is initiated by base loss. As a result, higher sequence coverage can be obtained while minimizing the appearance of other sequence related ions that originate from dissociations at other sites along the backbone. As the excitation amplitude increases, the other sequence informative cleavages begin to contribute and can therefore be observed, if so desired. Base loss contributes even under conditions in which $\mathrm{c} / \mathrm{y}$-ions comprise the major sequence informative ions. However, higher excitation amplitudes are necessary for the observation of the sequential fragmentation process comprised of base loss followed by $\mathrm{a}-\mathrm{B} / \mathrm{w}$-ion formation.

\section{Acknowledgments}

The authors acknowledge that this material is based upon work supported by the National Science Foundation under CHE0808380 and by the Purdue Research Foundation.

\section{References}

1. Mattick, J. S. Noncoding RNAs, the Architects of Eukaryotic Complexity. EMBO Rep. 2001, 2, 986-991.
2. Mattick, J. S. The Functional Genomics of Noncoding RNA. Science 2005, 309, 1527-1528.

3. Carninci, P., et al. The Transcriptional Landscape of the Mammalian Genome. Science 2005, 309, 1559-1563.

4. Aravin, A. A.; Hannon, G. J.; Brennecke, J. The Piwi-piRNA Pathway Provides an Adaptive Defense in the Transposon Arms Race. Science 2007, 318, 761-764.

5. Hahn, C. S.; Strauss, E. G.; Strauss, J. H. Dideoxy Sequencing of RNA Using Reverse Transcriptase. Methods Enzymol. 1989, 180, 121-130.

6. Cerny, R. L.; Tomer, K. B.; Gross, M. L.; Grotjahn, L. Fast Atom Bombardment Combined with Tandem Mass Spectrometry for the Study of Dinucleotides. Anal. Biochem. 1986, 156, 424-435.

7. Phillips, D. R.; McCloskey, J. A. A Comprehensive Study of the Low Energy Collision-induced Dissociation of Dinucleoside Monophosphates. Int. J. Mass Spectrom. Ion Processes 1993, 128, 61-82.

8. Wu, J.; McLuckey, S. A. Gas-Phase Fragmentation of Oligonucleotide Ions. Int. J. Mass Spectrom. 2004, 237, 197-241.

9. Kirpekar, F.; Krogh, T. N. RNA Fragmentation Studied in a MatrixAssisted Laser Desorption/Ionization Tandem Quadrupole/Orthogonal Time-of-Flight Mass Spectrometer. Rapid Commun. Mass Spectrom. 2001, 15, 8-14.

10. Schürch, S.; Bernal-Mendez, E.; Leumann, C. J. Electrospray Tandem Mass Spectrometry of Mixed-Sequence RNA/DNA Oligonucleotides. J. Am. Soc. Mass Spectrom. 2002, 13, 936-945.

11. Tromp, J. M.; Schürch, S. Gas-Phase Dissociation of Oligoribonucleotides and their Analogues Studied by Electrospray Ionization Tandem Mass Spectrometry. J. Am. Soc. Mass Spectrom. 2005, 16, 1262-1268.

12. Andersen, T. E.; Kirpekar, F.; Haselmann, K. F. RNA. Fragmentation in MALDI Mass Spectrometry Studied by H/D-Exchange: Mechanisms of General Applicability to Nucleic Acids. J. Am. Soc. Mass Spectrom. 2006, 17, 1353-1368.

13. Ni, J.; Pomerantz, C.; Rozenski, J.; Zhang, Y.; McCloskey, J. A. Interpretation of Oligonucleotide Mass Spectra for Determination of Sequence Using Electrospray Ionization and Tandem Mass Spectrometry. Anal. Chem. 1996, 68(13), 1989-1999.

14. McCloskey, J. A.; Whitehill, A. B.; Rozenski, J.; Qiu, F.; Crain, P. F. New Techniques for the Rapid Characterization of Oligonucleotides by Mass Spectrometry. Nucleosides Nucleotides 1999, 18(6/7), 1549-1553.

15. Mengel-Jørgensen, J.; Kirpekar, F. Detection of Pseudouridine and Other Modifications in tRNA by Cyanoethylation and MALDI Mass Spectrometry. Nucleic Acids Res. 2002, 30, e135.

16. Emmerechts, G.; Barbé, S.; Herdewijin, P.; Anné, J.; Rozenski, J. PostTranscriptional Modification Mapping in the Clostridium acetobutylicum $16 \mathrm{~S}$ rRNA by Mass Spectrometry and Reverse Transcriptase Assays. Nucleic Acids. Res. 2007, 35, 3494-3503.

17. McLuckey, S. A.; Goeringer, D. E. Slow Heating Methods in Tandem Mass Spectrometry. J. Mass Spectrom. 1997, 32, 461-474.

18. Xia, Y.; Chrisman, P. A.; Erickson. D. E.; Liu, J.; Liang, X.; Londry, F. A.; Yang, M. J.; McLuckey, S. A. Implementation of Ion/Ion Reactions in a Quadrupole/Time-of-Flight Tandem Mass Spectrometer. Anal. Chem. 2006, 78(12), 4146-4154.

19. Rozenski, J. Nucleic Acids Masspec Toolbox (Mongo Oligo Mass Calculator ver. 2.06). http://medlib.med.utah.edu/masspec.

20. McLuckey, S. A.; Vaidyanathan, G.; Habibi-Goudarzi, S. Charged vs. Neutral Nucleobase Loss from Multiply Charged Oligonucleotide Anions. J. Mass Spectrom. 1995, 30, 1222-1229.

21. Pan, S.; Verhoeven, K.; Lee, J. K. Investigation of the Initial Fragmentation of the Oligodeoxynucleotides in a Quadrupole Ion Trap: Charge Level-Related Base Loss. J. Am. Soc. Mass Spectrom. 2005, 16, 1853-1865.

22. Rodgers, M. T.; Campbell, S.; Marzluff, E. M.; Beauchamp, J. L. Low-Energy Collision-Induced Dissociation of Deprotonated Dinucleotides: Determination of the Energetically Favored Dissociation Pathways and the Relative Acidities of the Nucleic Acid Bases. Int. J. Mass Spectrom. 1994, 137, 121-149.

23. Habibi-Ghoudarzi, S.; McLuckey, S. A. Ion Trap Collisional Activation of the Deprotonated Deoxymononucleoside and Deoxydinucleoside Monophosphates. J. Am. Soc. Mass Spectrom. 1995, 6, 102-113.

24. McLuckey, S. A.; Habibi-Goudarzi, S. Decompositions of Multiply-Charged Oligonucleotide Anions. J. Am. Chem. Soc. 1993, 115, 12085-12095.

25. McLuckey, S. A.; Van Berkel, G. J.; Glish, G. L. Mass Spectrometry/ Mass Spectrometry of Small Multiply Charged Oligonucleotides. J. Am. Soc. Mass Spectrom. 1992, 3, 60-70.

26. Nordhoff, E.; Cramer, R.; Karas, M.; Hillenkamp, F.; Kirpekar, F.; Kristiansen, K.; Roepstorff, P. Ion Stability of Nucleic Acids in Infrared Matrix-Assisted Laser Desorption/Ionization Mass Spectrometry. $\mathrm{Nu}$ cleic Acids Res. 1993, 21, 3347-3357.

27. Tang, W.; Zhu, L.; Smith, L. M. Controlling DNA Fragmentation in MALDI-MS by Chemical Modification. Anal. Chem. 1997, 69, 302-312.

28. Wang, Z.; Wan, K. X.; Ramanathan, R.; Taylor, J. S.; Gross, M. L. Structure and Fragmentation Mechanisms of Isomeric T-Rich Oligodeoxynucleotides: A Comparison of Four Tandem Mass Spectrometric Methods. J. Am. Soc. Mass Spectrom. 1998, 9, 683-691.

29. Wan, K. X.; Gross, J.; Hillenkamp, F.; Gross, M. L. Fragmentation Mechanisms of Oligodeoxynucleotides Studied by H/D Exchange and Electrospray Ionization Tandem Mass Spectrometry. J. Am. Soc. Mass Spectrom. 2001, 12, 193-205.

30. Wan, K. X.; Gross, M. L. Fragmentation Mechanisms of Oligodeoxynucleotides: Effects of Replacing Phosphates with Methylphosphonates and Thymines with Other Bases in T-Rich Sequences. J. Am. Soc. Mass Spectrom. 2001, 12, 580-589. 